\title{
Geophysical and Geotechnical Site Characterization at Lagos Central Area of Lagos State, Nigeria.
}

\author{
Kayode F. Oyedele ${ }^{1}$, Rafiu B. Adegbola ${ }^{2}$, Olanike E. Abidoye ${ }^{2}$, Titiloye-Ajose M $^{1}$
}

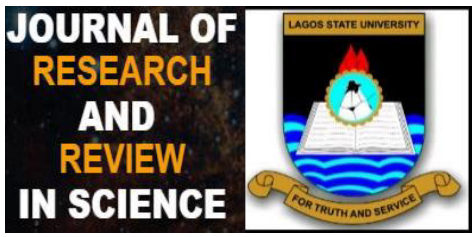

${ }^{1}$ Department of Geosciences, University of Lagos, Akoka, Lagos, Nigeria

${ }^{2}$ Department of Physics, Faculty of Science, Lagos State University, Ojo, Lagos State, Nigeria

\section{${ }^{*}$ Correspondence}

Rafiu Bolaji Adegbola, Department of Physics, Faculty of Science, Lagos State University, Ojo, Nigeria.

Email:adegbolaji@yahoo.com $+2348023070281$

\begin{abstract}
:
Introduction: Geophysical characterization refers to the collection of information associated with subsurface features. Geotechnical involves engineering structural performance studies which are used to obtain information on the physical properties of soil and rock around a site to design earthworks and foundations for proposed structures and for repair of distress to earthworks and structures caused by subsurface conditions. Aim: The study was aimed at characterizing the subsurface formations for the purpose of determining its capacity to withstand engineering structures.

Materials and Methods: Geophysical techniques involving eight (8) vertical electrical sounding (VES) and Wenner array were carried out with two (2) traverses. Geotechnical investigation involving cone penetration test (CPT) was also carried out.

Results: The results obtained were presented as 1D resistivity profiles and Pseudo-sections of 2-D. Three (3) geo-electric layers were delineated within the study area and these comprise of topsoil, peat or clay and silty sand. The CPT results were used in the calculation of bearing capacity using Bustamante and Gianeselli equation for pile foundations and Meyehorf equation to determine the maximum load the materials can withstand respectively.

Conclusion: The shallow subsurface geology was adjudged to be mechanically unstable with low penetration resistance values up to the depth of $11 \mathrm{~m}$. The methods conformed and confirmed that shallow foundation was considered unsuitable for the intended engineering structure.

Keywords: Meyehorf, Bustamante and Gianeselli, Subsurface, Geology, Unstable, Foundation.
\end{abstract}




\section{INTRODUCTION}

Geophysics can be used to detect spatial variations in the physical properties of the earth on a large scale. Geophysical characterization refers to the collection of information associated with subsurface features, such as burials on land or shipwrecks underwater, fault zones etc. Geotechnical involves engineering structural performance studies, cone penetration test is the most widely used method of Geotechnical investigations which are performed to obtain information on the physical properties of soil and rock around a site to design_earthworks and foundations for proposed structures and for repair of distress to earthworks and structures caused by subsurface conditions[1].

The most significant limitation of geophysical data is perhaps its non-uniqueness. Therefore, in order for an output geologic model to be accurate, the interpretation of geophysical data must be constrained and verified by ground truth acquired using intrusive methods. As a result of the need for constraints for geophysical data in engineering studies, geotechnical methods are usually employed. Geotechnical and geophysical surveys are often the most cost-effective and rapid means of obtaining subsurface information, especially over large study area [2] for building site investigations, land reclamation, dam site investigation and bridge construction [3].

Site investigations are done to acquire data that will facilitate successful foundation design, choice of foundation type and operational integrity of the proposed structure and using engineering geophysics makes it achievable. Hence, subsurface structure such as cavities, sinkholes, voids, fracture, faults etc. which are the major origin of hazards in civil engineering structures are determined using geophysical methods [4].

The electrical resistivity method is directly related to the nature, quantity, quality and distribution of the formation of water [5]. The greatest limitation of the resistivity sounding method is that it does not take into account horizontal changes in the subsurface resistivity. A more accurate model of the subsurface is a two-dimensional (2-D) model where the resistivity changes in the vertical direction, as well as in the horizontal direction along the survey line $[6 ; 7 ; 8]$.

Site characterization usually provides subsurface information that can assist civil engineers in the design of foundation of civil engineering structures [9]. In the recent times, reports on collapse/failure of engineering structures is becoming a daily occurrence in Lagos State and its environment, this necessitates proper subsurface investigation prior to construction work [10]. Site characterization for construction purposes has therefore become very essential so as to prevent loss of valuable lives and properties that always accompany such failures. Some reasons why buildings are liable to collapse are poor quality of building materials, bad design, poor supervision, salinity, old age of buildings and the most important is the subsurface conditions of the ground on which the buildings are sited. The design of a structure which is safe, durable and has low maintenance costs depends upon an adequate understanding of the nature of the ground on which such building was erected.

The study area was proposed for construction of a cable car station by the Lagos State Government and this was meant to serve as a means of public transportation. However, it was observed that the environment was poorly planned and several sinking/tilting of engineering structures existed (Plate 1) due to peculiar subsurface geology condition of the area. This survey was intended to delineating the lithology in this area and their relative strength.

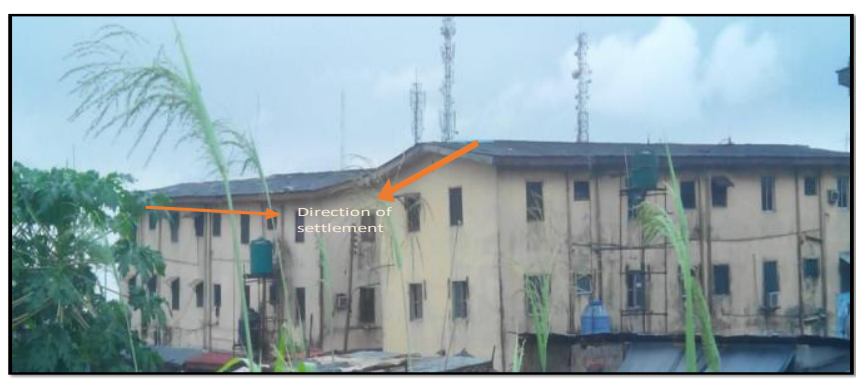

Plate 1: Tilting structures close to the study area.

\subsection{LOCATION AND GEOLOGY OF THE STUDY AREA}

Site Description: The survey area is located at Adeniji Adele area of Lagos State and lied within latitude $6^{\circ} 27^{\prime} 32.68 " \mathrm{~N}$, longitude $3^{\circ} 23^{\prime} 36.28 " \mathrm{E}$ and latitude $6^{\circ} 27^{\prime} 29.38$ "N, longitude $3^{\circ} 23^{\prime} 38^{\prime \prime} \mathrm{E}$ as shown in Plate 2. It was surrounded by canal on both sides which serves as the main drainage system of all the waste water coming from all the homes in this area which leads directly into the Lagos Lagoon. There is a residential estate situated directly on the right side of this site, several buildings within this estate have been observed to be sinking. This sinking effect would not have happened if proper geotechnical and geophysical investigations had been carried out to know the bearing capacity of the soil in the area. 


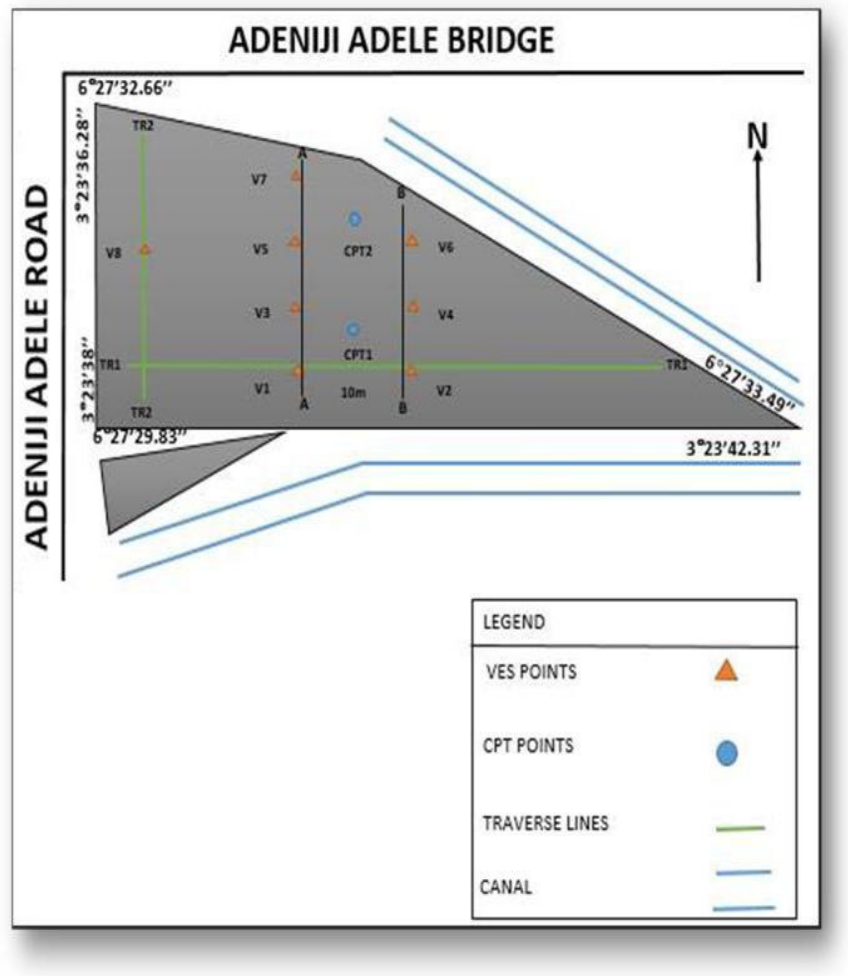

Plate 2: Map showing the study area.

\section{Geological settings}

Lagos state lies within the Benin (or Keta) Sedimentary basin with rocks consist of sand, clay and limestone. The geology of the Lagos State was dominated by a continuous and monotonous repetition of clayey and sandy horizons. These horizons show some discern able lateral continuation and are made up of successions of sandy-clay, sand, clayey sand and gravely sand sequences. The sand and clay sequences are intercalated with isolated and sometimes discontinuous bands of dark-brown to black peat and lignite. An east-west traverse along the coastline from the Badagry end to Akodo showed that some sand are found at the top of the section in all the boreholes along the coastline [11].

\section{MATERIAL AND METHODS}

Eight vertical electrical sounding (VES) points using direct current (D.C) resistivity method involving PASI Earth Resistivity meter were carried out in the study area. The data were acquired using Schlumberger array with electrodes spread that varied between 1-100 m for the base of the field and 1-200 $\mathrm{m}$ for the maximum length on the field. Measurements were taken at each VES point by expanding the current electrodes symmetrically about the centre of the spread. Two 2-D lines were run across the base and length of the field using Wenner array. Two geo-electric section profiles were chosen and interpreted by using Dipro software. The geotechnical survey method used here was the cone penetrometer test (CPT). The CPT was carried out on two points using a 2.5 tons Dutch cone penetrometer anchor. The test was carried out by securing the winch frame to the ground by means of anchors which provided the necessary power to push the cone into the ground. The cone and the tube were pushed together into the ground for 20 to $25 \mathrm{~cm}$; the cone was pushed ahead of the tube for $3.5 \mathrm{~cm}$ at a uniform rate of about $2 \mathrm{~cm} / \mathrm{s}$. The resistance of the penetration of the cone registered on the pressure gauge connected to the pressure capsule was recorded. Readings were taken at a depth interval of $0.25 \mathrm{~m}$.

The bearing capacity $\left(q_{t}\right)$ was determined from the cone tip resistance by using equation proposed by Bustamante and Gianeselli [12]. The equation is stated as follows:

$$
q_{t}=K_{b} q_{c}
$$

where, $\mathrm{K}_{\mathrm{b}}$ is an empirical bearing capacity factor that varies from 0.15 to 0.60 depending on the soil type and pile installation procedure shown on Table 1.

Table 1: Bearing capacity factor $\left(K_{b}\right)[12]$

\begin{tabular}{|l|c|c|}
\hline Soil type & Bored piles & Driven piles \\
\hline Clay-silt & 0.375 & 0.600 \\
\hline Sand-gravel & 0.150 & 0.375 \\
\hline Chalk & 0.200 & 0.400 \\
\hline
\end{tabular}

Bearing capacity was also calculated using Meyehorf equation to validate the result.

$$
q_{a}=2.7 q_{c} \quad \mathrm{KN} / \mathrm{m}^{2}
$$

For the purpose of foundation construction, an average value for penetrative resistance for competent subsurface materials was taken as $100 \mathrm{~kg} / \mathrm{cm}^{2}$. The corresponding value for allowable bearing capacity $\left(q_{a}\right)$ was $26460 \mathrm{KN} / \mathrm{m}^{2}$ while the value for the ultimate bearing capacity $q_{u}\left(K N / m^{2}\right)$ was given as 79380 $\mathrm{KN} / \mathrm{m}^{2}$ (using Meyehorf equation).

\section{RESULTS AND DISCUSSION}

\subsection{GEOELECTRICAL CHARACTERIZATION}

The 2-D sections were produced from the interpretations of the data obtained from Wenner array method as shown in (Fig.1). Here, low resistivity values that range from 1.3 to $1.9 \Omega \mathrm{m}$, were obtained along the section and these were probably attributed to clay or peat formation. 


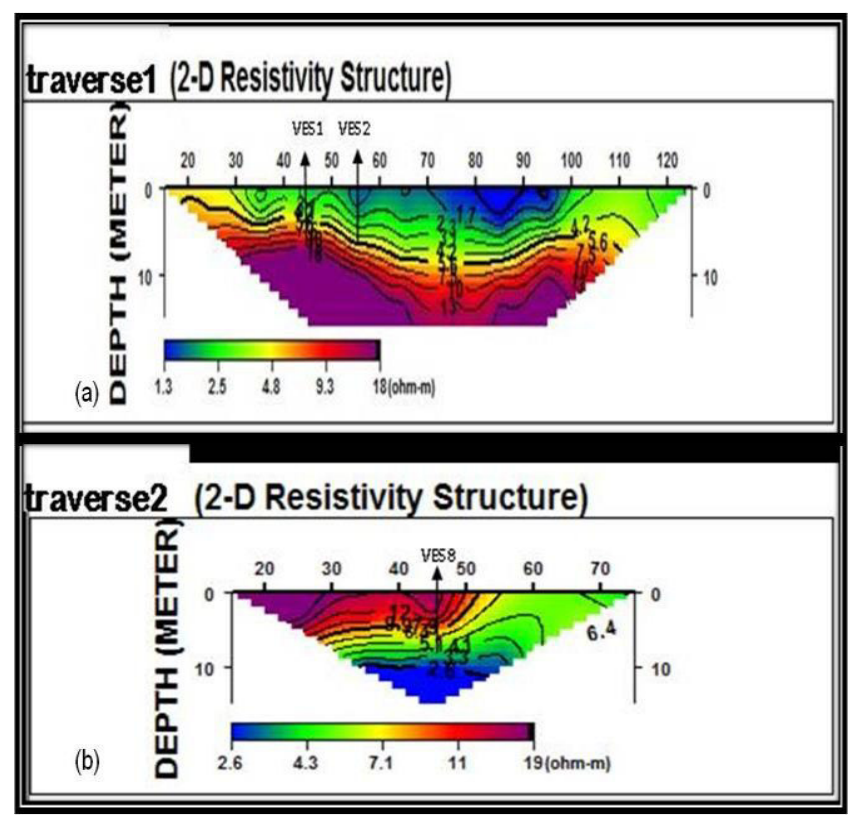

Fig. 1(a \& b): The Pseudo-sections of 2D at traverse 1 and 2.

The quantitative interpretation of the depth sounding curves was carried out by adopting the partial curve matching technique. The VES data obtained were plotted on a transparent overlay using log - log paper. The partial curve matching technique involving the use of standard two layer master curves and four auxiliary curves $(\mathrm{H}, \mathrm{K}, \mathrm{A}$, and $\mathrm{Q})$ were employed. This procedure required segment-by-segment curve matching starting from the position with shorter electrode spacing and moving towards those with longer spacing. The results of the VES curves obtained from the partial curve matching were then used to constrain the interpretation by the computer using iteration software known as WINRESIST. This invariably reduces overestimation of depths. The result of the computer iteration shows the quantitative analysis of the resistivity, thickness and depth of the subsurface layers (Fig. 2).
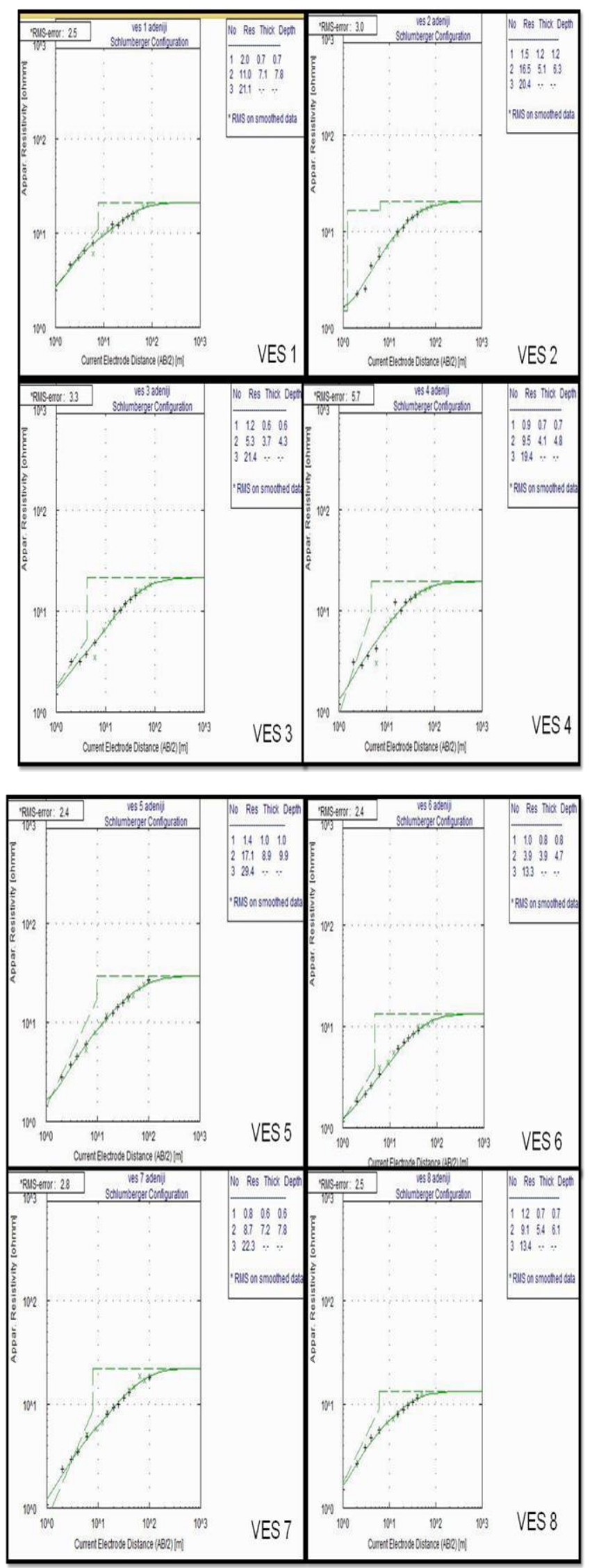

Fig. 2: The resistivity Curves and interpreted models for VES stations 1-8.

The geo-electric sections were generated to show relative vertical variation of resistivity at the subsurface. This involved the combination of eight interpreted VES results along the three traverses (Fig. 3). The geo- 
electric sections run from west to east in the survey area. The geo-electric section comprises of three layers with resistivity values that range from $0.6-29.4 \Omega \mathrm{m}$. This was made up of the topsoil, peat/clay and silty sand with peat/clay being the dominant soil type in this area. The topsoil has resistivity values that range from 0.8 to 2.0 $\Omega \mathrm{m}$ and thickness values that range from 0.4 to $1.2 \mathrm{~m}$. The peat/clay layers have resistivity values that range from 3.9 to $17.1 \Omega \mathrm{m}$ and thickness values that range from 3.7 to $8.9 \mathrm{~m}$. The silty sand layers have resistivity values that range from 13.3 to $29.4 \Omega \mathrm{m}$.

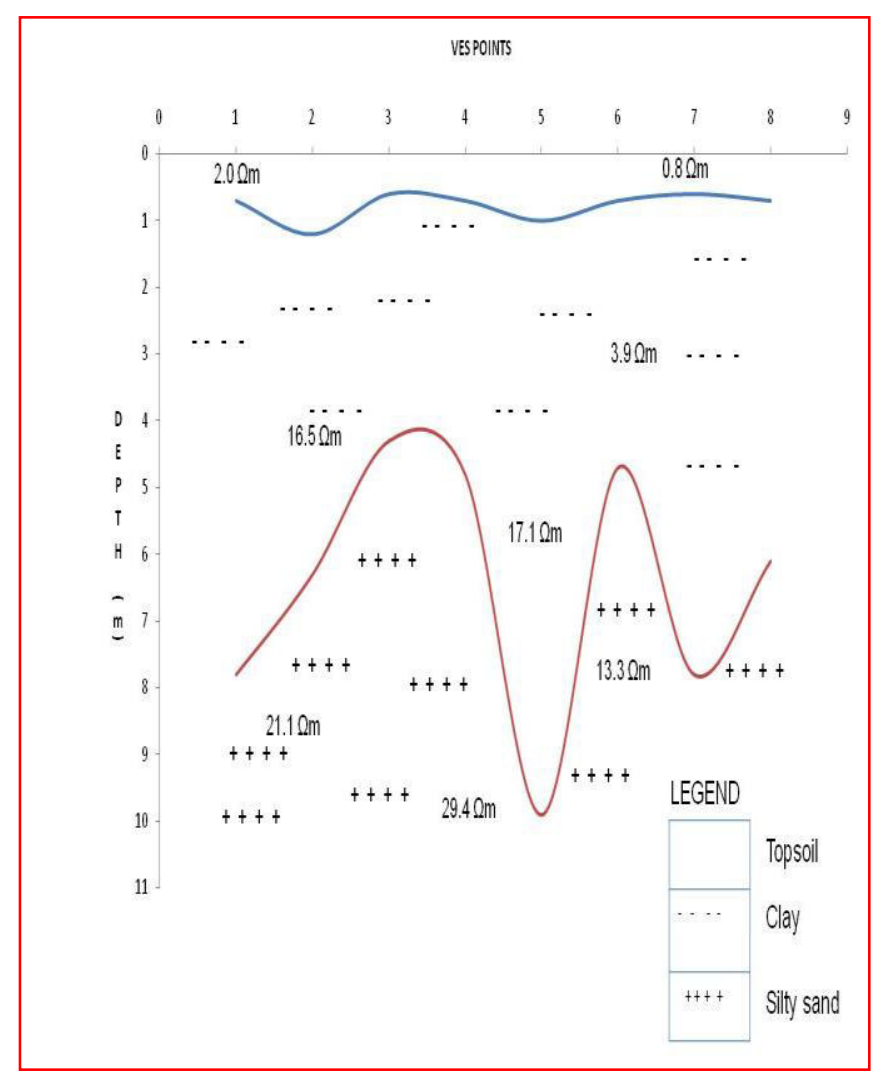

Fig. 3: Geo-electric section in the study area

\subsection{GEOTECHNICAL CHARACTERIZATION}

Two CPT readings were acquired and processed by plotting the cone resistance against the depth in each location point using Microsoft excel software (Fig. 4). The cone resistance reading for CPT 1 was recorded to a depth of $16.5 \mathrm{~m}$ in Figure $4 \mathrm{a}$, before the 2.5 Tons Dutch cone penetrometer anchor pulled. From the surface to a depth of about $11 \mathrm{~m}$, the cone penetration was quite smooth, a constant cone resistance reading of $5 \mathrm{~kg} / \mathrm{cm}^{2}$ was obtained and this was indicative of very fine and soft material which was probably peat or soft clay (same as CPT 2). From a depth of $11 \mathrm{~m}$ to $15.5 \mathrm{~m}$, cone resistance values which varied from 10 to $47 \mathrm{~kg} / \mathrm{cm}^{2}$ were obtained and this was indicative of loose sand. From a depth of about 15.75 to $16.5 \mathrm{~m}$, cone resistance values of about 65 to $125 \mathrm{~kg} / \mathrm{cm}^{2}$ were obtained and this was probably indicative of medium dense to dense sand. It was at this point that the anchor pulled.

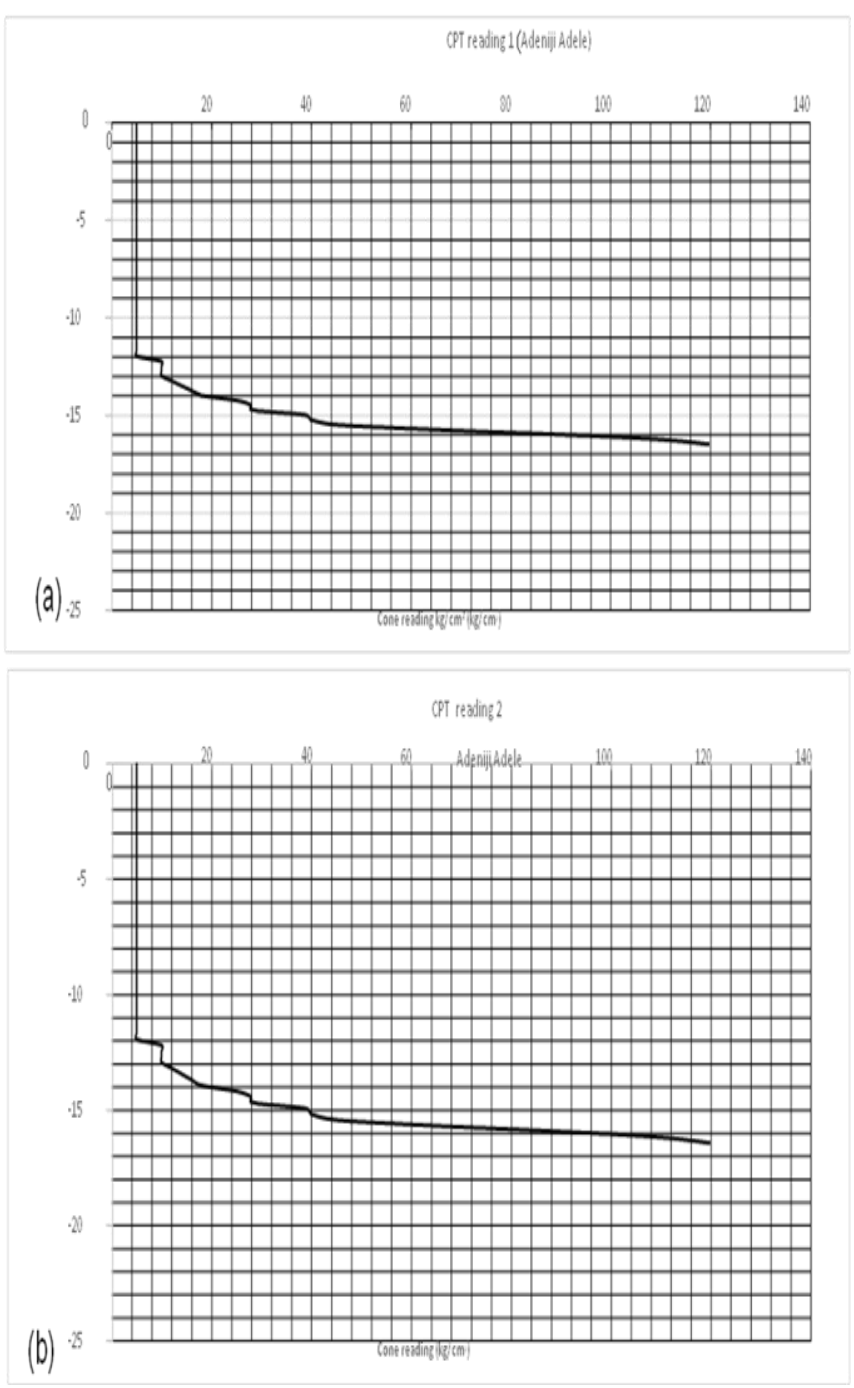

Fig. 4(a \& b): A graph of depth $(\mathrm{m})$ against Cone Resistance $\left(\mathrm{Kg} / \mathrm{cm}^{2}\right)$ for CPT 1and 2

The bearing capacities of the different materials in the subsurface were calculated from the CPT results using the Bustamante and Gianeselli (1982) equation (Eqn. 1). The cut-off values $(\mathrm{Kb})$ used for the calculations are 0.375 (Bored piles) and 0.600 (Driven piles) which fell under clay-silt soil type (Table 1). From the derived bearing capacity values for CPT 1 , the maximum bearing capacity obtained was 4412.992514 KN/m² for bored piles and 7060.788022 $\mathrm{KN} / \mathrm{m}^{2}$ for driven piles. For CPT 2, the maximum bearing capacity obtained was $4412.992514 \mathrm{KN} / \mathrm{m}^{2}$ for bored piles and $7060.788022 \mathrm{KN} / \mathrm{m}^{2}$ for driven piles. The derived bearing capacity obtained using the Meyehorf equation ranged from 1323.9 to 31773.6 $\mathrm{KN} / \mathrm{m}^{2}$ for CPT 1 and CPT 2. Comparing the derived bearing capacity values with the allowable bearing capacity $\left(q_{a}\right)$ which was $26460 \mathrm{KN} / \mathrm{m}^{2}$, made it possible to identify the competent materials in the subsurface. The competent materials at the study area were found to range between 16.25 to $16.50 \mathrm{~m}$ while the bearing capacity values range from 29215.8 to $31773.6 \mathrm{KN} / \mathrm{m}^{2}$ for both CPT 1 and CPT 2. 


\subsection{INTEGRATION OF VES, 2-D IMAGING AND CPT RESULTS}

The electrical imaging results revealed materials with low resistivity values that ranged from $(1-19 \Omega \mathrm{m})$ which were delineated to be clay or peat. These materials appeared to be present in all over the traversed area up to the depth investigated. The VES method also delineated three geo-electric layers. The second layers were observed to be of low resistive materials which could be attributed to peat or clay formation. The results were constrained by CPT results obtained within the same traverses. The CPT results indicated materials with low shear strength within the depth range of 0 to $11 \mathrm{~m}$ corroborating the results obtained from the geophysical survey. This shows that the low resistivity material beneath the subsurface may be peat / clay formation. The maximum depth of this layer on both the geo-electric sections and CPT sections ranged from 8.9 to $11.0 \mathrm{~m}$. The bearing capacity results obtained also appear to fall within the medium to dense sand layers at a depth greater than $11.0 \mathrm{~m}$

\section{CONCLUSION}

Integration of both geophysical and geotechnical methods have shown to be adequate in the successful characterization of the subsurface geology within the study area. Results obtained from both techniques employed have shown clearly that shallow foundation was not feasible in the area. Hence, it could be concluded and recommended that only deep foundation in the form of pilling to the competent layer at a depth greater than $11 \mathrm{~m}$ would be adequate for any engineering structure in the area.

\section{ACKNOWLEDGEMENTS}

Not applicable.

\section{COMPETING INTERESTS}

No competing interests exist.

\section{AUTHORS' CONTRIBUTIONS}

$1^{\text {st }}$ Author designed the project with a view to attending the problem, $2^{\text {nd }}$ Author did the processing and interpretations. However, $3^{\text {rd }}$ and $4^{\text {th }}$ Authors managed the field work and the discussions. All Authors wrote the first draft of the manuscript. All authors read and approved the final manuscript.

\section{REFERENCES}

1. Oyedele KF, Olorode DO. Site Investigations of Subsurface Conditions Using Electrical Resistivity Method and Cone Penetration Test at Medina Estate, Gbagada, Lagos, Nigeria. World Applied Sciences Journal. 2010; 11(9), 1097-1104.
2. Sirles $P$, Neil A, Neil C, Rick H. Geophysical Methods Commonly Employed for Geotechnical Site Characterization. Transportation Research Circular. 2008; Number E- C130, 1-35.

3. Oyedele KF, Oladele S, Okoh C. GeoAssessment of Subsurface Condition in Magodo, Brook Estate, Lagos Nigeria. International Journal of Advanced Scientific and Technical Research. 2012; 2(4), 731-741.

4. Ozegin KO, Oseghale AO, Audu AL, Ofotokun EJ. An application of the 2-D D.C. Resistivity method in Building Site Investigation - a case study: Southsouth Nigeria. Journal of Environment and Earth Science. 2013; 3(2), 108-112.

5. Adepelumi AA, Olorunfemi MO, Falebita DE, Bayowa OG. Structural mapping of coastal plain sands using engineering geophysical technique: Lagos Nigeria Case Study. Natural Science. 2009; 1, 2-9.

6. Loke $\mathrm{MH}$. Electrical imaging surveys for environmental and engineering studies: $A$ practical guide to 2-D and 3-D surveys. 2000.

7. Sarma VS. Electrical Resistivity(ER), Self Potential (SP), Induced Polarisation (IP), Spectral Induced Polarisation (SIP) and Electrical Resistivity Tomography (ERT) prospection in NGRI for the past 50 years-A Brief Review. J. Ind. Geophys. Union. 2014; 18(2), 245-272.

8. Oyeyemi KD, Aizebeokhai AP, Oladunjoye MA. Integrated Geophysical and Geochemical Investigations of Saline Water Intrusion in a Coastal Alluvial Terrain, Southwestern Nigeria. International Journal of Applied Environmental Sciences. 2015; 10(4), 1275-1288.

9. Oyedele KF, Oladele S, Adedoyin O. Application of Geophysical and Geotechnical Methods to Site Characterization for Construction Purposes at Ikoyi, Lagos, Nigeria. Journal of Earth Sciences and Geotechnical Engineering. 2011; 1(1), 87-100.

10. Ayolabi EA, Adegbola RB. Application of MASW in road failure investigation. Arab $\mathrm{J}$. geosci. 2013; 7(10) 1-7.

11. Oteri AU. Coastal groundwater resource abstraction, quality and related environmental concerns: Lagos state case study. LSWRC Workshop. 2013.

12. Bustamante M, Gianeselli L. Pile bearing capacity predictions by means of static penetrometer CPT. Proceedings of the 2nd European Symposium on Penetration Testing. Amsterdam. 1982; ESOPT-II, 493-5 